\title{
The future of research in Tourette syndrome
}

\author{
Andrea E. Cavanna ${ }^{\mathrm{a}, \mathrm{b}, *}$, Conor Kavanagh ${ }^{\mathrm{a}}$ and Mary M. Robertson ${ }^{\mathrm{c}, \mathrm{d}}$ \\ ${ }^{a}$ Department of Neuropsychiatry, University of Birmingham and BSMHFT, Birmingham, UK \\ ${ }^{\mathrm{b}}$ Sobell Department of Motor Neuroscience and Movement Disorders, Institute of Neurology, UCL, London, UK \\ ${ }^{c}$ Department of Mental Health Sciences, UCL, London, UK \\ ${ }^{\mathrm{d}}$ Department of Neurology, St George's Hospital and Medical School, London, UK
}

\begin{abstract}
Tourette syndrome (TS) is a neurological condition first described by Georges Gilles de la Tourette in 1885 . TS was largely thought of as a rare and bizarre condition until the 1960s, when the beneficial effects of neuroleptics on tic symptoms led to an exponential increase in neuroscientific research. Today TS is known to be a relatively common condition that is frequently misdiagnosed due to a combination of its variable manifestation and the waxing and waning of tic frequency and severity. Although there has been a paucity of research on TS compared to other movement disorders, in recent years TS has garnered increasing interest and has shown a number of novel and complex sides, about which much is yet to be learnt. The present article discusses where research has taken us thus far and where it is heading in all the major facets of this fascinating condition.
\end{abstract}

Keywords: Tourette syndrome, tics, research, phenomenology, pathophysiology, genetics, treatment

\section{Introduction}

Tourette syndrome (TS) has fascinated clinicians and researchers alike over the decades [1,2], but has attracted relatively little research until recently [3]. This article focuses on where this research has taken us and where it is heading.

The first important area of research in TS is about the clinical phenomenology and the relationship between tics and behavioural symptoms. TS is commonly associated with attention deficit and hyperactivity disorder (ADHD), obsessive-compulsive disorder (OCD), depression and personality disorders and in fact clinical studies conducted both in specialist clinics $[4,5]$ and in the wider community [6] have consistently shown that only $8-12 \%$ of patients with TS have no other psychopathology [7]. Research has been performed to determine the nature of the relationship between TS and these co-morbidities and has suggested that spe-

\footnotetext{
* Corresponding author: Andrea Eugenio Cavanna, MD, PhD, Department of Neuropsychiatry, Birmingham and Solihull Mental Health NHS Foundation Trust, The Barberry National Centre for Mental Health, 25 Vincent Drive, Birmingham B15 2FG, UK. Email: andrea.cavanna@bsmhft.nhs.uk.
}

cific obsessive-compulsive symptoms can represent an alternative phenotypic expression of TS, whilst depression seems to be multifactorial in origin, with a major contribution by the co-morbidity with OCD and ADHD rather than TS itself. Of course there remain unclear points, for example whether tic disorders plus ADHD represent a separate nosological entity, a combination of two independent pathologies or a phenotype subgroup of either ADHD or TS. Also, the exact nature of the relationship between personality disorders and TS remains unknown [8].

The term endophenotype was coined in 1967 by Gottesman and Shields [9] to refer to a biological trait that is an intermediary between certain genes and a pattern of behavior. Exciting new studies are currently being conducted to find endophenotypes in the field of TS and tic disorders. For example, it has been suggested that pre-frontal cortex thinning and reduction in caudate volume may be endophenotypes for TS, as they correlate with tic severity [10]. Another example is the fine-motor skills demonstrated on the Purdue Pegboard test, which may also serve as a helpful endophenotype by giving a rough estimate of the level of basal ganglia dysfunction [11].

One of the major challenges for clinicians who see children with TS is to be able to predict the clinical 
course or long-term outcome of the condition. Tics generally appear between the ages of 4-6, reach their worst-ever severity around the ages of 10 and 12 and in the vast majority of patients improve during the course of adolescence [12]. Although it appears that the presence of co-morbid conditions in childhood correlate poorly with tic severity in adulthood $[13,14]$ putative endophenotypes such as poor fine motor skills [11] and smaller caudate volumes in childhood seem to be associated with increased adulthood tic severity [15]. Neuroimaging data also suggest that certain regions in the brain may be involved in persistent TS, however further longitudinal studies are required to confirm this [16]. Despite these preliminary findings, there are still no clinical measures that can allow us to reliably predict whose symptoms will persist into adulthood.

The pathophysiology of TS is still largely unknown. Research suggests that the dorsolateral pre-frontal cortex (DLPFC) [17] and the basal ganglia (in particular the caudate region [18] which receives input from the DLPFC [19]) are involved in the pathogenesis of TS. More recently, post-mortem studies have implicated a deficiency of parvalbumin striatal interneurons in the development of TS symptoms [20]. Gene-environment interaction studies on the development of parvalbumin interneurons are ongoing [21] and will likely provide a better understanding of the causes of TS and assist the development of new treatments in the future.

Various techniques and methodologies are currently being used to investigate the pathophysiology of TS. For instance, structural and functional imaging have found evidence for compensatory neuroplastic changes (particularly in the prefrontal cortex and corpus callosum), possibly reflecting active efforts to gain control of the tic symptoms [22,23]. Neurophysiological investigations have demonstrated negative potentials occurring $100 \mathrm{~ms}$ before tic expression, suggesting that simple motor tics might originate from deep brain structures such as the striatal centres [24]. Animal models are receiving increasing attention to examine the pathophysiology of TS. In one study, sera from patients with TS containing anti-neural and anti-nuclear antibodies were injected into rats resulting in oral stereotypies, a finding consistent with autoimmune etiology in a subset of patients with TS [25].

The genetic aspects of TS have proven unexpectedly challenging. Segregation analyses have suggested multiple inheritance patterns in TS [26], and other genetic studies have identified a number of candidate regions which are currently being investigated [27,28]. Although rare, these mutations can make a key con- tribution to our understanding of disease pathogenesis in TS. TS was once thought to be a unitary condition [29], but recent clinical studies using statistical techniques such as principal-component factor analysis, hierarchical cluster analysis and latent class analysis have suggested there may be multiple distinct TS phenotypes [30]. In order to increase the likelihood of finding genes responsible for TS precise phenotypic definition should be incorporated in future genetic studies.

Despite the number of available therapeutic options, the treatment of TS is still suboptimal. The majority of treatment options for tics are pharmacological [31, 32] although non-pharmacological treatments have increasingly been advocated. These include behavioural techniques, such as Habit Reversal Therapy (HRT) and Exposure and Response Prevention (ERP) [33], and stereotactic neurosurgery, namely Deep Brain Stimulation (DBS). Randomized controlled studies comparing the efficacy of behavioral techniques to pharmacological therapies are needed. Moreover, although HRT has shown a durable response over time, long-term studies are currently lacking for ERP [34]. Treatment-resistant patients whose tics significantly impair their healthrelated quality of life may be candidates for DBS (usually targeting the thalamus or globus pallidus - pars interna), which has shown to have the potential to improve both tics and psychiatric co-morbidities [35]. Larger randomized controlled trials are needed to confirm the efficacy of specific DBS targets along with their safety, as, although rare, adverse effects such as sedation and changes in sexual function have been reported [36].

Finally, a few recent studies have made insightful contributions to our understanding of cognitive, emotional and social aspects of TS, inspired by novel approaches from the field of social cognition [37-41]. Subtle difficulties in theory of mind and other socially relevant skills have been identified and linked to underlying functional abnormalities within the fronto-basal pathways that appear to be involved In tic generation. From a clinical perspective, these findings could explain at least some of the difficulties encountered in everyday life by patients with TS and could complement the rapidly expanding research area on the determinants of quality of life in this complex condition [4244].

Across both sides of the Atlantic, research has gathered speed over recent years and consequently more is known about TS than ever before. As corollary of the swell in research, more and more questions are being asked for future researchers to tackle in a field that is becoming increasingly fascinating. 


\section{Acknowledgements}

The authors are grateful to Tourette Syndrome Association USA and Tourettes Action UK for their ongoing support.

\section{References}

[1] Rickards H, Cavanna AE. Gilles de la Tourette: The man behind the syndrome. J Psychosom Res. 2009; 67: 469-474.

[2] Jankovic J. Tourette's syndrome. N Engl J Med. 2001; 345: 1184-1192.

[3] Mariam N, Cavanna AE. The most cited works in Tourette syndrome. J Child Neurol 2012 in press.

[4] Freeman RD, Fast DK, Burd L, Kerbashian J, Robertson MM, Sandor P. An international perspective on Tourette syndrome: Selected findings from 3500 individuals in 22 countries. Dev Med Child Neurol. 2000; 42: 436-437.

[5] Cavanna AE, Critchley HD, Orth M, Stern JS, Young M-B, Robertson MM. Dissecting the Gilles de la Tourette spectrum: A factor analytic study on 639 patients. J Neurol Neurosurg Psychiatry. 2011; 82: 1320-1323.

[6] Khalifa N, Knorring ALV. Psychopathology in a Swedish population of school children with tic disorders. J Am Acad Child Adolesc Psychiatry. 2006; 46: 1346-1353.

[7] Robertson M. Tourette syndrome, associated conditions and the complexities of treatment. Brain. 2000; 123: 425-462.

[8] Cavanna AE, Servo S, Monaco F, Robertson MM. The behavioural spectrum of Gilles de la Tourette syndrome. J Neuropsychiatry Clin Neurosci. 2009; 21: 13-23.

[9] Gottesman II, Shields J. A polygenic theory of schizophrenia. Proc Natl Acad Sci USA. 1967; 58: 199-205.

[10] Robertson MM. The Gilles De La Tourette syndrome: the current status. Arch Dis Child Educ Pract Ed. 2012 in press.

[11] Bloch MH, Sukhodolsky DG, Leckman JF, Schultz RT. Finemotor skill deficits in childhood predict adulthood tic severity and global psychosocial functioning in Tourette's syndrome. J Child Psychol Psychiatry. 2006; 47: 551-559.

[12] Bloch MH, Leckman JF. Clinical course of Tourette syndrome. J Psychosom Res. 2009; 67: 497-501.

[13] Bloch MH, Peterson BS, Scahill L, Otka J, Katsovich L, Zhang $\mathrm{H}$, Leckman JF. Adulthood outcome of tic and obsessivecompulsive symptom severity in children with TS. Arch Pediatr Adolesc Med. 2006; 160: 65-69.

[14] Cavanna AE, David K, Orth M, Robertson MM. Predictors during childhood of future health-related quality of life in adults with Gilles de la Tourette syndrome. Eur J Paediatr Neurol. 2012 in press.

[15] Bloch MH, Leckman JF, Zhu H, Peterson BS. Caudate volumes in childhood predict symptom severity in adults with Tourette syndrome. Neurology. 2005; 65: 1253-1258.

[16] Peterson BS, Staib L, Scahill L, Zhang H, Anderson C, Leckman JF, et al. Regional brain and ventricular volumes in Tourette syndrome. Arch Gen Psychiatry. 2001; 58: 427-440.

[17] Peterson BS, Thomas P, Kane MJ, Scahill L, Zhang H, Bronen $\mathrm{R}$, et al. Basal ganglia volumes in patients with Gilles de la Tourette syndrome. Arch Gen Psychiatry. 2003; 60: 415-424.

[18] Yoon DY, Gause CD, Leckman JF, Singer HS. Frontal dopaminergic abnormality in Tourette syndrome: A postmortem analysis. J Neurol Sci. 2007; 255: 50-56.
[19] Obeso JA, Rodriguez-Oroz MC, Benitez-Temino B, Blesa FJ, Guridi K, Marin C, Rodriguez M. Functional organization of the basal ganglia: therapeutic implications for Parkinson's disease. Mov Disord. 2008: 23(Suppl 3): S548-559.

[20] Kataoka Y, Kalanithi PS, Grantz H, Schwartz ML, Saper C, Leckman JF, Vaccarino FM. Decreased number of parvalbumin and cholinergic interneurons in the striatum of individuals with Tourette syndrome. J Comp Neurol. 2010; 518: 277-291.

[21] Wonders CP, Anderson SA. The origin and specification of cortical interneurons. Nat Rev Neurosci. 2006; 7: 687-696.

[22] Jackson SR, Parkinson A, Jung J, Ryan SE, Morgan PS, Hollis C, Jackson GM. Compensatory neural reorganization in Tourette syndrome. Curr Biol. 2011; 21: 580-585.

[23] Cavanna AE, Stecco A, Rickards H, Servo S, Terazzi E, Peterson B, et al. Corpus callosum abnormalities in Tourette syndrome: An MRI-DTI study of monozygotic twins. J Neurol Neurosurg Psychiatry. 2010; 81: 533-535.

[24] Obeso JA, Rothwell JC, Marsden CD. The neurophysiology of Tourette syndrome. Adv Neurol. 1982; 35: 105-114.

[25] Taylor JR, Morshed SA, Parveen S, Mercandante MT, Scahill L, Peterson BS, et al. An animal model of Tourette's Syndrome. Am J Psychiatry. 2002; 159: 657-660.

[26] Keen Kim D, Freimer NB. Genetics and epidemiology of Tourette syndrome. J Chil Neurol. 2006; 21: 665-671.

[27] Abelson JF, Kwan KY, O'Roak BJ, Baek DY, Stillman AA, Morgan TM, et al. Sequence variants in SLITRK1 are associated with Tourette syndrome. Science. 2005; 310: 317-320.

[28] Ercan-Sencicek AG, Stillman AA, Ghosh AK, Bilguvar K, O'Roak BJ, Mason CE, et al. L-histidine decarboxylase and Tourette's Syndrome. N Engl J Med. 2010; 362: 1901-1908.

[29] Alsobrook JP 2nd, Pauls DL. A factor analysis of tic symptoms in Gilles de la Tourette syndrome. Am J Psychiatry. 2002; 159: 291-296.

[30] Robertson MM, Cavanna AE. The Gilles de la Tourette Syndrome: A principal component factor analytic study of a large pedigree. Psychiatr Genet. 2007; 17: 143-152.

[31] Roessner V, Plessen KJ, Rothenberger A, Ludolph AG, Rizzo $\mathrm{R}$, Skov L, et al. European Clinical guidelines for Tourette syndrome and other tic disorders. Part II: pharmacological treatment. Eur Child Adolesc Psychiatry. 2011; 20: 173-196.

[32] Eddy CM, Rickards HE, Cavanna AE. Treatment strategies for tics in Tourette syndrome. Ther Adv Neurol Dis. 2011; 4: 25-45.

[33] Verdellen CW, Keijsers GP, Cath DC, Hoogduin CA. Exposure with response prevention versus habit reversal in Tourette's syndrome: a controlled study. Behav Res Ther. 2004; 42: 501-511.

[34] Piacentini J, Woods DW, Scahill L, Wilhelm S, Peterson AL, Chang S, et al. Behaviour therapy for children with Tourette disorder: A randomized controlled trial. JAMA. 2010; 303: 1929-1937.

[35] Cavanna AE, Eddy CM, Mitchell R, Pall H, Mitchell I. An approach to deep brain stimulation for severe treatmentrefractory Tourette syndrome: the UK perspective. Br J Neurosurg. 2011; 25: 38-44.

[36] Piedad JCP, Rickards HE, Cavanna AE. What patients with Gilles de la Tourette syndrome should be treated with Deep Brain Stimulation and what is the best target? Neurosurgery. 2012; 71: 173-192.

[37] Eddy CM, Rizzo R, Cavanna AE. Neuropsychological aspects of Tourette syndrome: A review. J Psychosom Res. 2009; 67: 503-513.

[38] Eddy C, Mitchell IJ, Beck SR, Cavanna AE, Rickards H. Al- 
tered attribution of intention in Tourette's syndrome. J Neuropsychiatry Clin Neurosci. 2010; 22: 348-351.

[39] Eddy CM, Mitchell IJ, Beck SR, Cavanna AE, Rickards H Impaired comprehension of non-literal language in Tourette syndrome. Cogn Behav Neurol. 2010; 23: 178-184.

[40] Eddy CM, Mitchell IJ, Beck SR, Cavanna AE, Rickards H. Social reasoning in Tourette syndrome. Cogn Neuropsychiatry. 2011; 16: 326-347.

[41] Channon S, Drury H, Gafson L, Stern J, Robertson MM. Judgements of social inappropriateness in adults with Tourette syndrome. Cogn Neuropsychiatry. 2012; 17(3): 246-261.
[42] Eddy CM, Cavanna AE, Gulisano M, Agodi A, Barchitta M, Calì P, Robertson MM, Rizzo R. Clinical correlates of quality of life in Tourette syndrome. Mov Disord. 2011; 26: 735-738.

[43] Eddy CM, Rizzo R, Gulisano M, Agodi A, Barchitta M, Calì P, Robertson MM, Cavanna AE. Quality of life in young people with Tourette syndrome: A controlled study. J Neurol. 2011; 258: 291-301.

[44] Müller-Vahl K, Dodel I, Muller N, Münchau A, Reese JP, Balzer-Geldsetzer $\mathrm{M}$, et al. Health-related quality of life in patients with Gilles de la Tourette's syndrome. Mov Disord. 2010; 3: 309-314. 


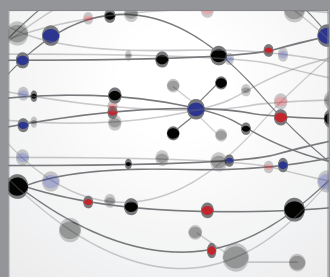

The Scientific World Journal
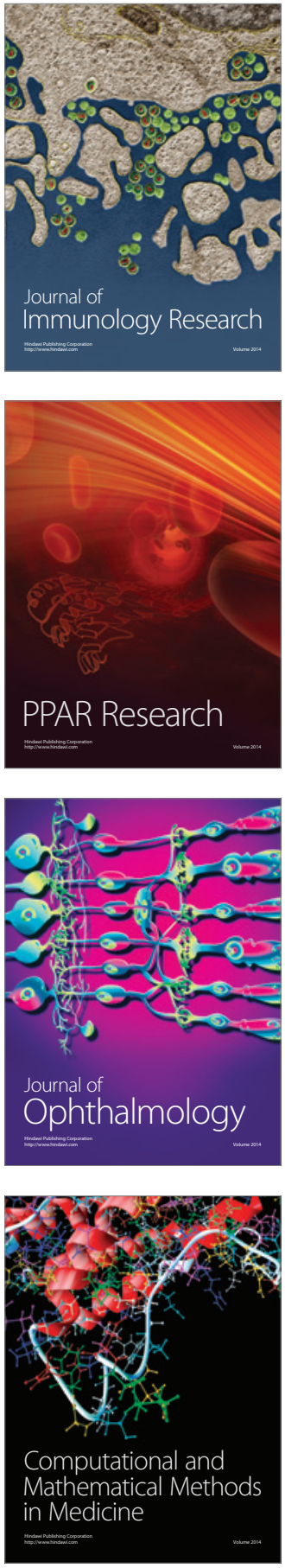

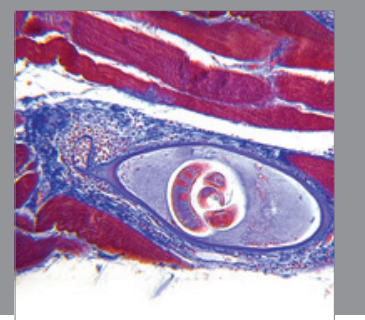

Gastroenterology

Research and Practice
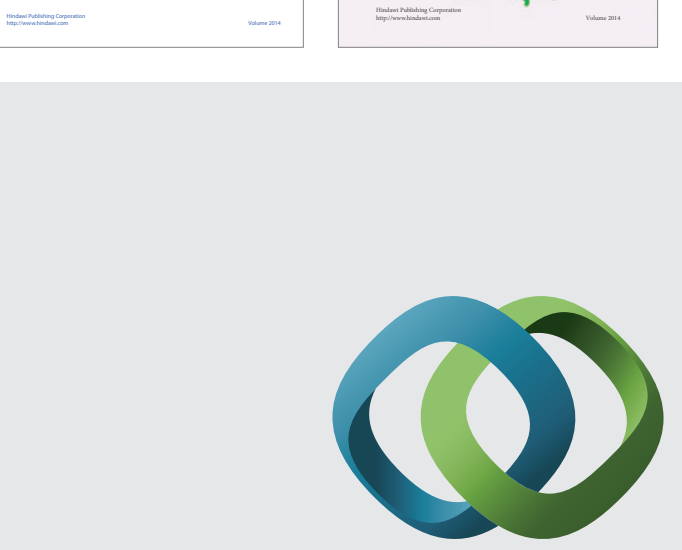

\section{Hindawi}

Submit your manuscripts at

http://www.hindawi.com
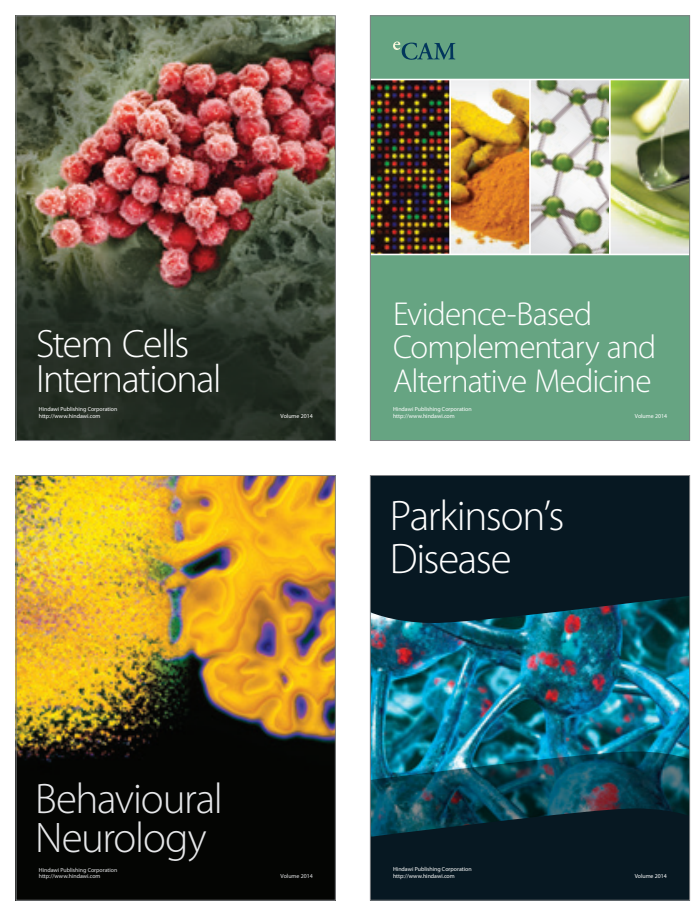

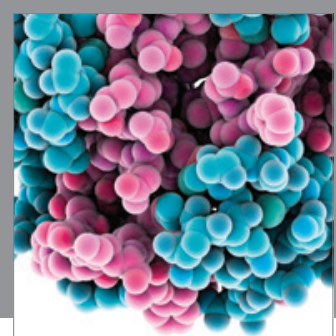

Journal of
Diabetes Research

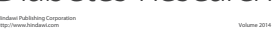

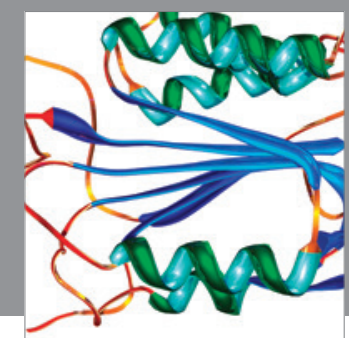

Disease Markers
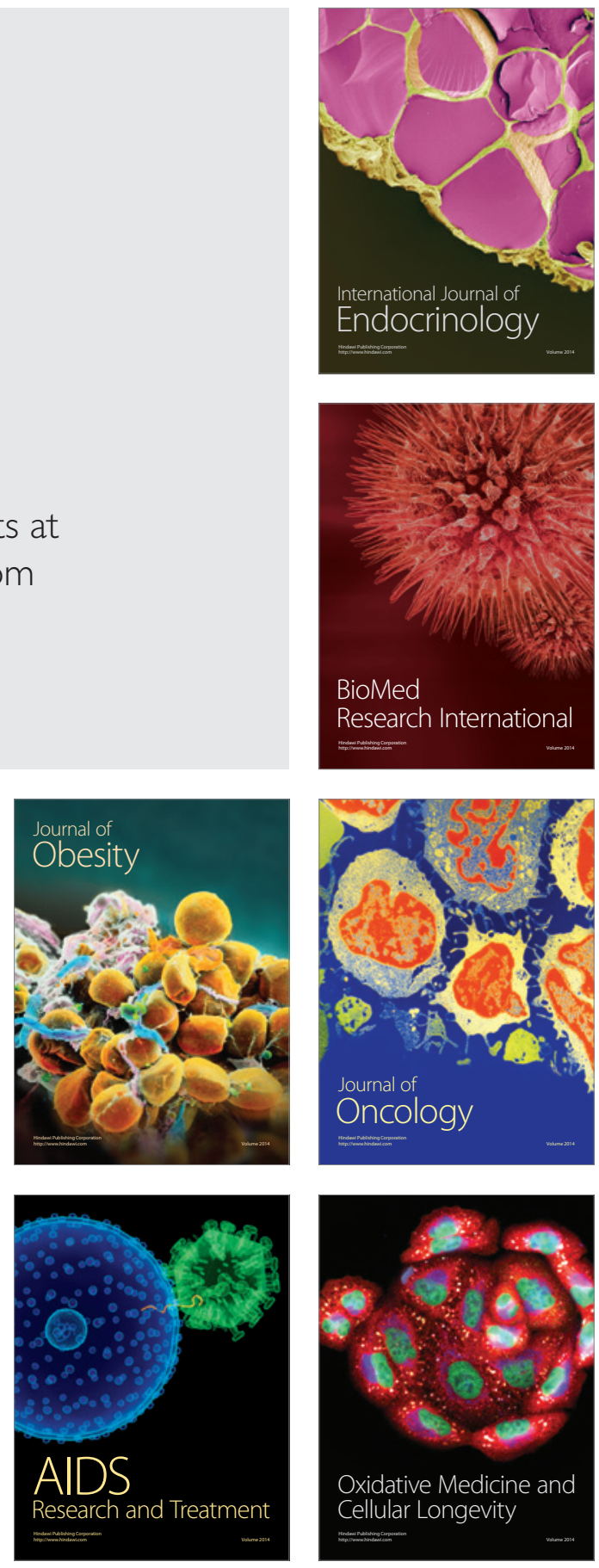